\title{
HYDATID CYST OF THE KIDNEY IN A CHILD
}

\author{
BY \\ M. E. BROUGHTON \\ From the Duchess of York Hospital for Babies, Manchester
}

(RECEIVED FOR PUBLICATION MAY 19, 1957)

The incidence of hydatid disease varies considerably in different parts of the world. It is common in South America, Australia and parts of Asia; for example, in Beirut, Syria, $0.75 \%$ of hospital admissions over a 10-year period were patients with echinococcus cysts (Baurys, 1952). In Great Britain there are no figures of value about the incidence of hydatid disease because there is no proper system of reporting primary cases infested here as distinct from those infested overseas. The total primary cases are probably fewer than 50 per year, of which nearly half are patients who become infested in endemic areas in other countries (Bensted, 1957). The only endemic area in Great Britain is South Wales; the disease is five times commoner in Wales than in England (Mackay, 1956). Wolfe (1943) reviewed 34 cases, which had occurred over a period of 12 years, from the hospital reports of the Royal Infirmary, Cardiff.

The disease is rarely seen after the fourth decade of life and about $26.2 \%$ of hydatid cysts occur in patients under 15 years of age. The organic distribution of cysts in children is liver $76.2 \%$, lung $11.1 \%$, brain $4.3 \%$ and kidney $1.2 \%$ (Dew, 1928). Gray (1953) reviewed the cases of hydatid disease found in the children of Cardiff and did not mention a cyst in the kidney. This confirms the impression drawn from Bensted's and Dew's figures that renal hydatid cyst in a child in Great Britain is a very rare disease.

\section{Case Report}

Philip C, aged 7 years, was sent to the Duchess of York Hospital because at a routine school examination he was found to have an enlarged liver. He had no complaints and was leading a normal, active life at school. His bowels, micturition, sleep, appetite and weight were all satisfactory. He had lived in Stockport, an industrial town, all his life, apart from one holiday at the seaside in North Wales. In 1953 the family kept a puppy for one year but no evidence was obtained to suggest that the puppy was the source of infection.

In 1952 the child was admitted to hospital with a pyrexia of unknown origin, possibly glandular fever or benign lymphocytosis. The abnormal physical signs were a low-grade pyrexia and an enlarged liver. On admission the total white cell count was $45,000 / \mathrm{c} . \mathrm{mm}$. (lymphocytes $80 \%$, polymorphs $20 \%$ ). A Paul Bunnell test was positive at 1:64 and two weeks later it was positive at 1:4. A month after admission the child was well, the pyrexia had subsided and the liver was not palpable. The total white cell count was then $13,400 / \mathrm{c} . \mathrm{mm}$ (polymorphs $47 \%$, lymphocytes $41 \%$, eosinophils $10 \%$, monocytes $2 \%$ ). No cause was found for the high eosinophil count at the time.

On admission on July 12,1956, he was a pale thin child but appeared active and well. In the abdomen an ill-defined mass could be palpated in the right renal area. The liver and spleen were not palpable. The cardiovascular, respiratory, lymphatic and central nervous systems were normal.

A straight radiograph of the abdomen showed a large calcified cyst, kidney-shaped, lying in the region of the right kidney (Figs. 1A and 1B).

A blood count gave a total white cell count of $12,000 /$ c.mm. (polymorphs $50 \%$, lymphocytes $36 \%$, eosinophils $9 \%$, monocytes $5 \%$ ), Hb $86 \%$, E.S.R. $5 \mathrm{~mm}$. in one hour.

No albumin, sugar or acetone were found in the urine and in the deposit a few epithelial cells but no pus cells or red cells were seen.

Liver function tests were within normal limits.

The blood urea level was $38 \mathrm{mg}$. \%.

A Mantoux test $(1: 1,000)$ was negative.

An intravenous pyelogram showed that the cyst was situated in the right renal area but did not involve the pelvis of the kidney (Fig. 2). The pyelogram of the left kidney was normal.

A provisional diagnosis of simple cyst or neoplasm of the kidney was made.

On July $16 \mathrm{Mr}$. Kirkman explored the right renal area through an oblique incision. A large cystic mass with an opaque firm wall adherent to the lateral aspect of the kidney, from which it appeared to arise, was found (Fig. 3). A right nephrectomy was performed.

Dr. K. W. Lodge reported that the specimen was a kidney measuring $9 \times 2 \times 4 \mathrm{~cm}$. with an attached cystic mass $9 \mathrm{~cm}$. in diameter.

On section the cyst was firmly adherent to the capsule of the kidney and was compressing the kidney tissue but not invading it. The cyst contained clear colourless fluid and had a thin wall in which there was a deposit of calcium and a smooth gelatinous lining. It was not 


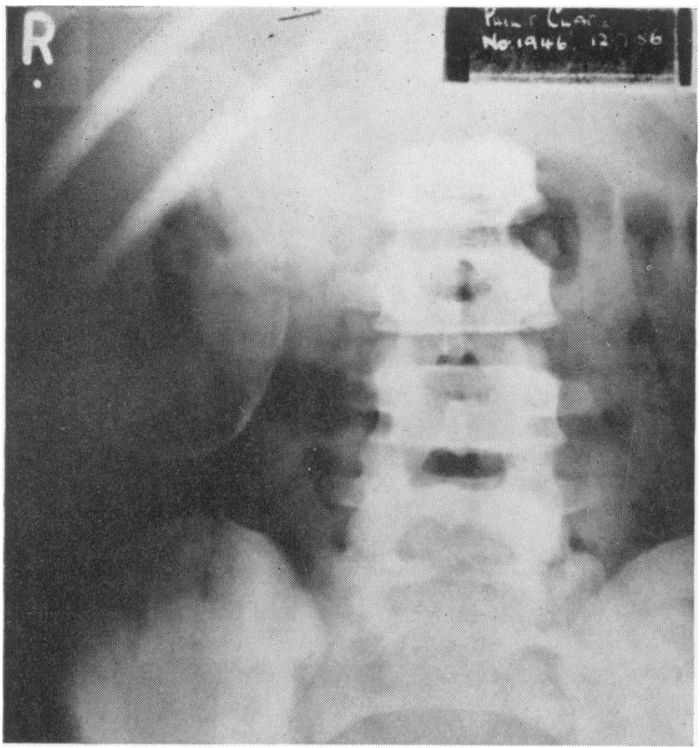

FIG. 1A.-Anterio-posterior radiograph of the right abdomen showing the cyst in the right renal area.

in communication with the pelvis of the kidney and at the upper pole there was a multilocular area.

A portion of the attached ureter showed no abnormality. The cyst wall was composed of fibrous tissue lined by

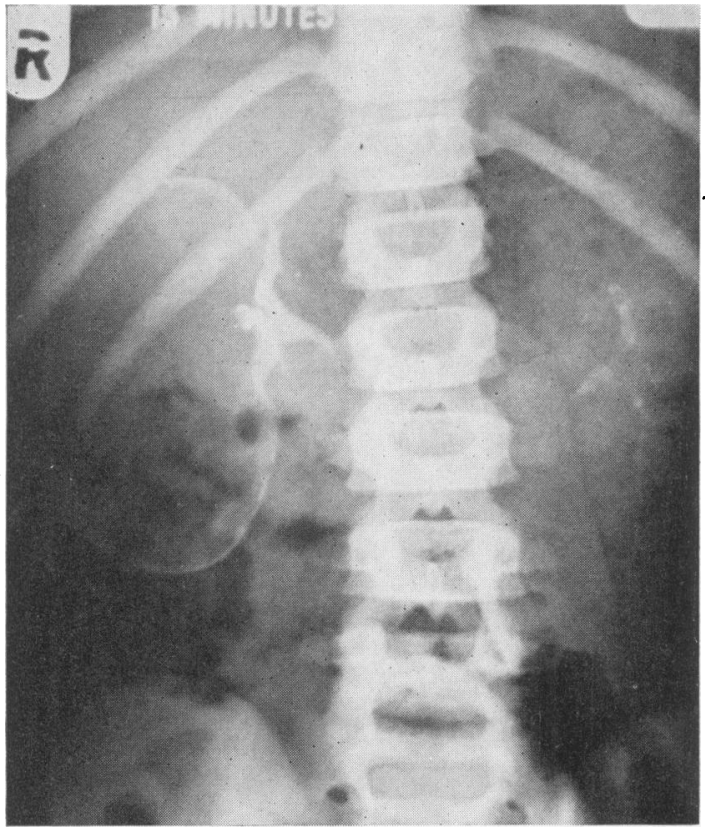

Fig. 2.-Intravenous pyelogram showing the cyst related to the right renal pelvis.

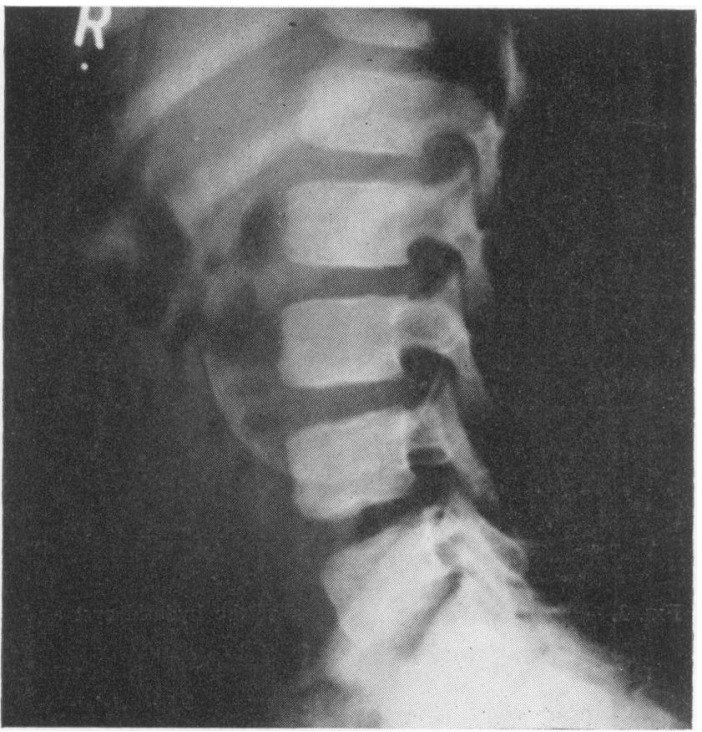

FIG. 1B.-Straight lateral radiograph showing the position of the cyst in relation to the right renal area.

a layer of amorphous acellular material bordered by a single layer of flattened epithelium. The kidney adjacent to the cyst showed a marked inflammatory reaction in which the predominant cells were eosinophils. Attached to the cyst lining and in the kidney pelvis there were a few parasites which showed a peripheral capsule and a central area containing a sucker and invaginated hooklike structures. The appearances were those of a cyst containing parasites which closely resembled the Echinococcus granulosus.

The child made a good post-operative recovery. A - Casoni test performed on July 28 gave a negative result. Radiographs of the chest and long bones were normal. He was discharged on July 30, and on September 3 he was readmitted for cystoscopy when no abnormality was found in the bladder. The urine was examined for scolices, hooklets and hydatid material but none were found. The total white cell count was $7,200 / \mathrm{c} . \mathrm{mm}$ (eosinophils $3 \%$ ). Casoni tests were performed on his family and were negative. The child is being followed up as an out-patient and when seen last in December, 1956, was very well.

\section{Discussion}

There are several points of interest. It is probable that the pyrexia of unknown origin in 1952 was the reaction caused by the primary infestation of the echinococcus and would account for the high eosinophil count in 1952. It is interesting that the eosinophil count has fallen from $1,080 /$ c.mm. to 216/c.mm. since operation.

The kidney was removed because the possibility of malignancy could not be excluded at the time and 


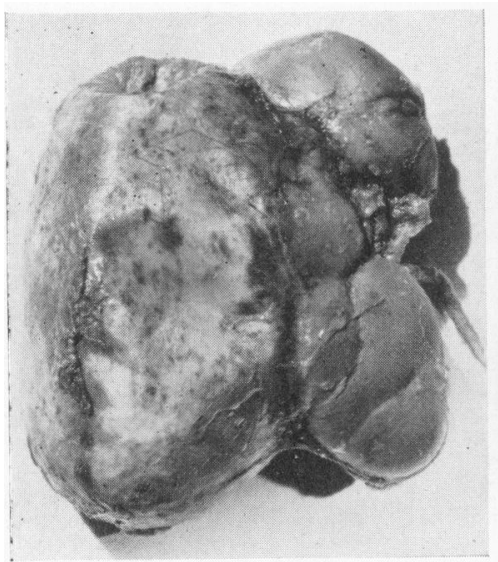

(a)

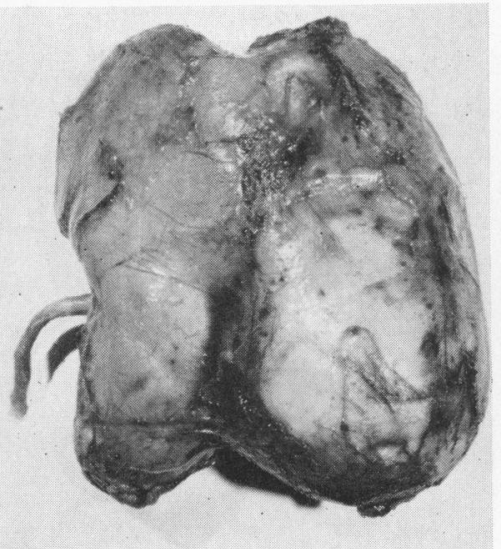

(b)

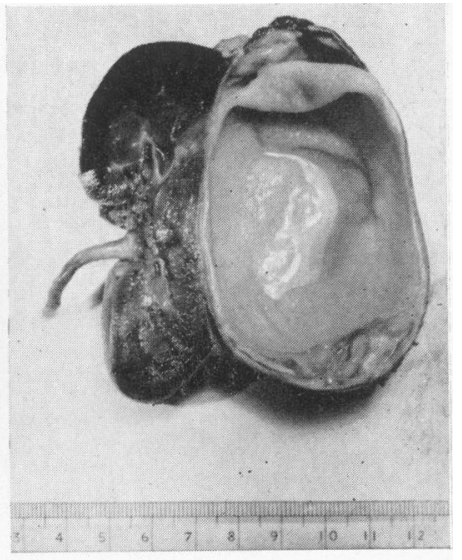

(c)

FIG. 3.-Photographs showing views of the hydatid cyst and right kidney removed at operation: (a) Anterior view; (b) posterior view; (c) on section.

the mass was too adherent to the kidney to dissect it away completely. Even if the diagnosis had been made pre-operatively a nephrectomy is generally considered to be the treatment of choice for renal hydatid cyst. In this particular case hooklets in the pelvis of the kidney made nephrectomy essential.

The prognosis for the child is good, if it is a single cyst, and it is thought to be so. The cyst was completely removed and there was no evidence of spread down the ureter.

\section{Summary}

A short survey of the incidence of hydatid disease is given. A case of hydatid cyst of the kidney in a 7-year-old boy is described together with the relevant investigations and treatment. Certain points arising from the history are discussed.

I wish to thank Mr. N. F. Kirkman for permission to report this case and also for his helpful encouragement. My thanks are also due to Miss Gibbon, of the South Manchester Hospital Management Committee Department of Medical Illustration, for the photographs, and to the nursing staff of the Duchess of York Hospital.

\section{REFERENCES]}

Baurys, W. (1952). J. Urol. (Baltimore), 68, 441.

Bensted, H. J. (1957). Personal communication.

Dew, H. R. (1928). Hydatid Disease, pp. 27, 91. Australasian Medical Publishing Co., Sydney.

Gray, O. P. (1953). Archives of Disease in Childhood, 28, 243.

Mackay, R. I. (1956). Postgrad. med. J., 32, 16.

Wolfe, H. R. I. (1943). Pancet, 1, 795. 